\title{
A FAMILY OUTBREAK OF TINEA GAPITIS DUE TO TRICHOPHYTON VIOLACEUM IN MICHIGAN. ITS GONTROL WITH GRISEOFULVIN
}

\author{
by \\ Florante C. Bocobo, M. D. *), Leo J. Miedler, M. D.*) \\ \& Gordon A. EAdIE, M. D. **).
}

(25.V.1961)

(with 6 figs.)

Trichophyton violaceum, BoDIn, is a major cause of dermatophytic infection of the hair and skin in the Mediterranean region, eastern Europe, the Near East, and Asia $(1,2,3)$. Its isolation is particularly frequent in the following countries: Portugal (4), Spain (5), southern France (6), Italy (7), Greece (8), Turkey (9), Israel (10), Egypt (11), Algeria (12), Tunisia (13), Morocco (14), Yugoslavia (15), Bulgaria (16), Rumania (17), Poland (18), Russia (19), China (20), India $(21,22)$ and southern Australia (23, 24). The Mediterranean Sea is so encircled by countries endemic for Trichophyton violaceum that the organism has been described as a circumMediterranean species (25).

Trichophytosis violaceum is non-prevalent in the Western Hemisphere, except for a few endemic areas. São Paulo, Brazil, has the highest reported incidence in the Americas $(26,27)$, with the original infection presumably introduced from Portugal and Italy. BLANK (28) notes that endothrix ringworm due mainly to Trichophyton violaceum and Trichophyton tonsurans is endemic in rural eastern Quebec, Canada. Craig, Blank \& Danby (29) observed an increase of these cases in Montreal, Canada, especially among immigrants. In four months during 1951, at the Royal Victoria Hospital, they observed twelve cases of endothrix tinea capitis, three of which were due to Trichophyton violaceum. Reports from other American

From the Department of Dermatology and Institute of Industrial Health*, University of Michigan, Ann Arbor, Michigan, and the Wayne County Health Department**, Eloise, Michigan.

The griseofulvin (Fulvicin) tablets used in this study were provided by Schering Corporation, Bloomfield, New Jersey, through Dr. G. KENNETH Hawxins.

We gratefully acknowledge the help extended by Mrs. Matilde Dozen, Mrs. Miriam Harris, Mr. George Miller and Mr. Walter Boehme of the Norris and Jefferson Schools in Nankin, Michigan. 
countries, such as Argentina (30), Uruguay (31), Peru (32), Cuba (33) and Mexico (34), which do mention Trrichophyton violaceum show its relatively infrequent isolation.

The organism, likewise, is uncommon in the United States. Single isolated cases due to Trichophyton violaceum have been described in New York City $(35,36,37)$, Philadelphia (38), and East St. Louis (39). Only a few statistical studies of the incidence of dermatophytes record the isolation of this fungus. The reported figures from these few areas are low:

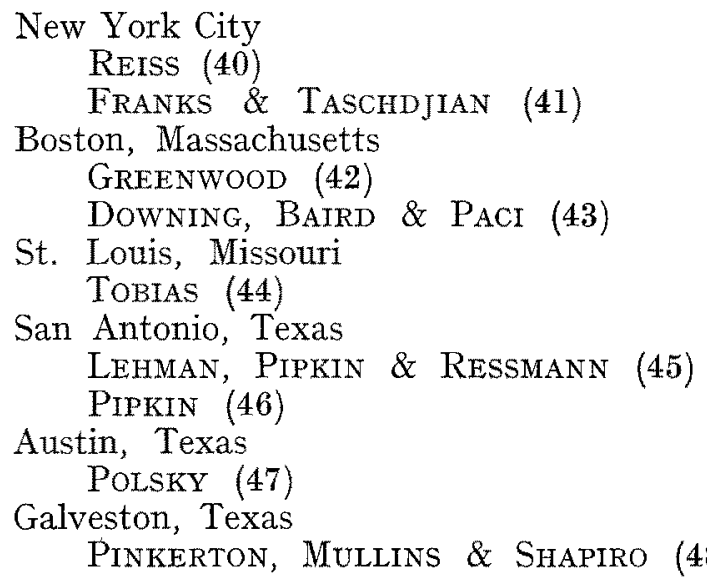

REISS $(40$

FRANKS \& TASCHDJIAN (41)

Antonio, Texas

Lehman, Pipkin \& Ressmann (45)

in, Texas

Pinkerton, Mullins \& Shapiro

$4.2 \%$

$0.5 \%$

$1.2 \%$

$2.4 \%$

$7.0 \%$

$5.5 \%$

$0.2 \%$

An exception to the above reports of sporadic cases was the outbreak of tinea capitis among the inmates of the Willowbrook State School (for mentally retarded persons) in Staten Island, New York, reported by Hazen, Little \& Mordaunt (49) and by Rosenthal, FISHER \& FURNARI (50). Of 88 patients with clinical changes of tinea capitis, $44(50 \%)$ yielded cultures of Trichophyton violacewm.

In Michigan, the only recorded isolation of Trichophyton violaceum was made by CAWLEY \& HORNE (51) in the University of Michigan Hospital from a 55 year old, white female, with an erythematous, scaly, gyrate lesion across the forehead and discolored deformity and brittleness of all the finger nails. Trichophyton gypseum was cultured from the glabrous lesion and Trichophyton violaceum from the involved nails. In a cultural study of 173 cases of ringworm from northeastern Michigan covering several medium-sized industrial cities, a number of small towns and many farms throughout thirteen counties, GeORG, HAND \& MENGES (52) did not encounter a single case of trichophytosis caused by $T r$. violaceum

The present report describes an outbreak of tinea capitis caused by Trichophyton violaceum in five siblings of a family of eight residing in the township of Nankin, an outlying suburban area west of Detroit, Michigan. 


\section{DESCRIPTION OF OUTBREAK}

The present outbreak was discovered during the routine clinical and cultural examination of children in the Clinic of the Wayne County Health Center. During the latter part of May, 1960, the children of the family described in this report were referred to the Clinic by their school nurse because of scalp changes. Clinical specimens were obtained for mycological studies and attention was focused on the entire family when the cultures showed growth of Trichophyton violaceum.

\section{Case Reports:}

1. L.G., Sr., 33 years old, male, American Indian, construction worker.

The scalp of the patient did not show any clinical change, except for slight diffuse balding, particularly at the frontal area.

Direct and cultural examinations of hair specimens were negative.

2. J. G., 23 years old, female, Caucasian, housewife.

The patient had no scalp complaints although on examination there was found minimal diffuse dandruff type of scaling over the vertex of the head. There was no hair loss.

Mycological examinations failed to reveal any dermatophyte.

3. A.G., 9 years old, female, white.

The patient had scaling and slight loss of hair on the top of the head for about a year previous to being seen in the Clinic.

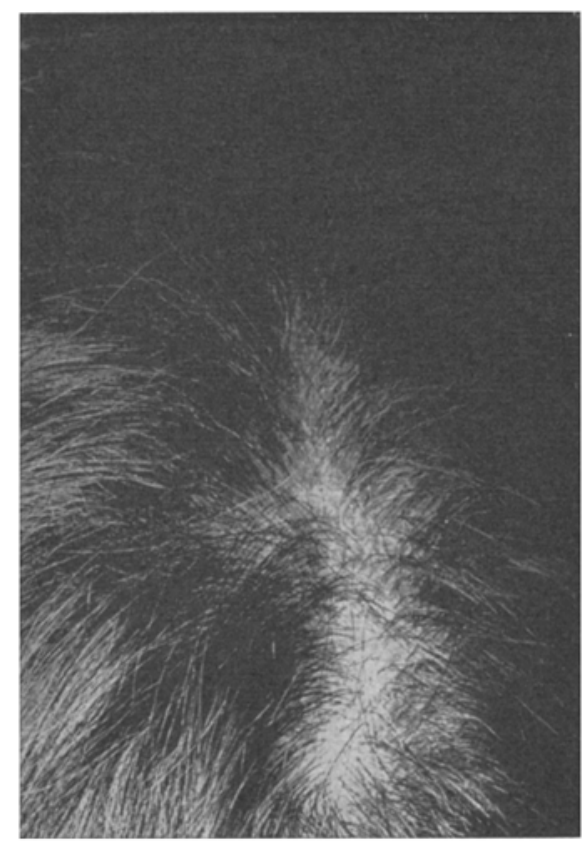

Fig. 1. Clinical picture of A.G. showing scaling and loss of hair. Mycopathol. et Mycol. Appl. XVI, 3. 
On examination there was found on the vertex of the head a patch, about $1.5 \mathrm{~cm}$ in diameter, with moderate dandruff-like dry scaling and slight loss of hair (Fig 1). The borders of the patch were indistinct. There was no other sign of activity as erythema or folliculitis. No "black dots" or broken hairs were seen. There was no fluorescence of the patch under Wood's light. Although the direct examinations of the hairs were negative, Trichophyton violaceum was repeatedly cultured from her specimens.

4. L.M.G., 7 years old, female, white.

For one year, the patient had had scattered areas of scaling on the head.

The patient presented a major patch, $2.5 \mathrm{~cm}$ in diameter, with scaling and slight loss of hair on the vertex of the head (Fig. 2). On closer examination excoriations, slightly erythematous papules, and suspicious "blacls dots" were seen in the patch. Smaller similarly involved areas were scattered in the occipital region. The lesions were Wood's light negative. The child also had

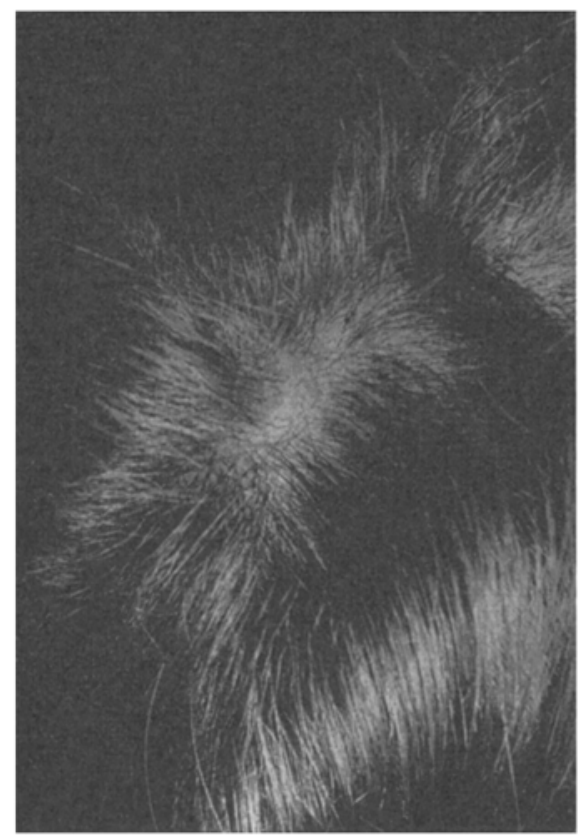

Fig. 2. Clinical picture of L.M.G., showing scaling and loss of hair.

two contiguous erythemato-squamous ringworm lesions, about one inch in diameter each, with active borders, on the lateral aspect of the left elbow. $\mathrm{KOH}$ examinations of the specimens from the scalp were positive. Cultures were repeatediy positive for Trichophyton violaceum. Examinations of specimens from the glabrous lesions on the left elbow were negative.

5. L.G., Jr., 6 years old, male, white.

Scalp changes on the patient had been observed for about a year.

$\mathrm{On}$ examination of the head, areas of scaling and moderate hair loss with $1-2 \mathrm{~cm}$ diameters were seen scattered over the vertex and occiput. No inflammatory signs or "black dots" were observed. The lesions were non-fluorescent under Wood's light. Fungous elements were seen by $\mathrm{KOH}$ examination of the hairs. Trichophyton violacewm was isolated by culture. 
6. W.G., 5 years old, male, white.

Scalp changes were of one year's duration.

There was diffuse dandruff-like scaling and slight loss of hair over the vertex of the head with small oval areas of similar scaling around the area. No active inflammation or "black dots" were seen. Wood's light examination was negative for fluorescence.

$\mathrm{KOH}$ examinations were positive and cultures showed Trichophyton violacem.

7. B.G., 3 years old, male, white.

The present illness began a year ago as scaling on the top of the head.

The patient on examination had slight loss of hair and diffuse dandruff-like scaling over the vertex without any active inflammation or "black dots." There was no fluorescence of the involved areas under Wood's light. KOH examinations were positive and cultures showed Trichophyton violaceum.

8. D. $G_{n}, 1-1 / 2$ years old, male, white.

Both direct and cultural examinations of the hairs taken from the patient were negative.

\section{Epidemiological Data}

The father of the family is an American Indian from North Carolina while the mother, of Swedish and German descent, is from Kentucky. The family came to Nankin, Michigan, two years ago from Harlan, a town in the eastern part of Kentucky. They had lived in Harlan for eight years and are unaware of any epidemic of scalp disease in that town. The children arrived in Michigan without known scalp involvement.

The family has made only one trip out of town during the last two years: to Springfield, Ohio, in winter, 1960. The children were already infected at that time.

Barbering is done in the family, either by the father or by the mother, never by a commercial barber. The children do not go to the movies. They do not use a school bus. The family pet is a dog and does not show any evidence of mycotic skin infection.

The mother claims that the oldest child, A. G., was the first to show clinical changes on the scalp, followed in a short time by W. G., L.M.G., L.G., Jr., and B.G. in that order. The three older children (A.G., L.M.G., and L.G., Jr.) attend school - A.G., to Jefferson School and the other two, to Norris School in Nankin township.

In an attempt to trace the source of infection of the present outbreak and to uncover any possible focus in the schools attended by these children, the two schools were surveyed. Norris School had an enrollment of 308 children and Jefferson School, 536 children. Both schools cover classes from kindergarten to sixth grade. All the children were examined for scalp changes, such as scaling, broken hairs, loss of hair, folliculitis, erythema, etc. Children showing such changes, no matter how minimal, were further studied and clinical specimens obtained from the scalp for mycological examinations. Of the 536 children in Jefferson School, only nine had clinical changes. One of these nine gave a positive culture of $\mathrm{Mi}$ crosporon audouinii. No Trichophyton violaceum was discovered. Of the 308 children in Norris School, twelve presented clinical 
changes. One gave a positive culture of Microsporon audouinii, and another, a double culture of Trichophyton violaceum and Trichophyton tonsurans.

The latter child was further followed up and the rest of her family studied. She was 10 years old, caucasian, and presented a pronounced diffuse dandruff-like scaling of most of the scalp. Subsequent to the initial isolation of Trichophyton violaceum and Trichophyton tonsurans, however, repeated $\mathrm{KOH}$ examinations and cultures of specimens obtained at intervals of 3-4 weeks from the child failed to show any dermatophyte. Four of her siblings also gave negative results on mycological examination.

Five dust samples were collected from random areas in the residence of the infected $G$ family and subjected to procedures using mice for isolation of dermatophytes as previously described (53). The results were negative. Attempts similar to those followed by MACKENZIE (54) for recovering Trichophyton tonsurans from extrahuman sources likewise failed to isolate Trichophyton violaceum from combs used by the infected children presently studied.

\section{Mycological Studies}

The strains of Trichophyton violaceum isolated from this outbreak were typical. The infected hairs seen in $\mathrm{KOH}$ mounts under the microscope were usually filled with large, endothrix spores which lay in rows axially along the hairs (Fig. 3). The affected hairs were seen

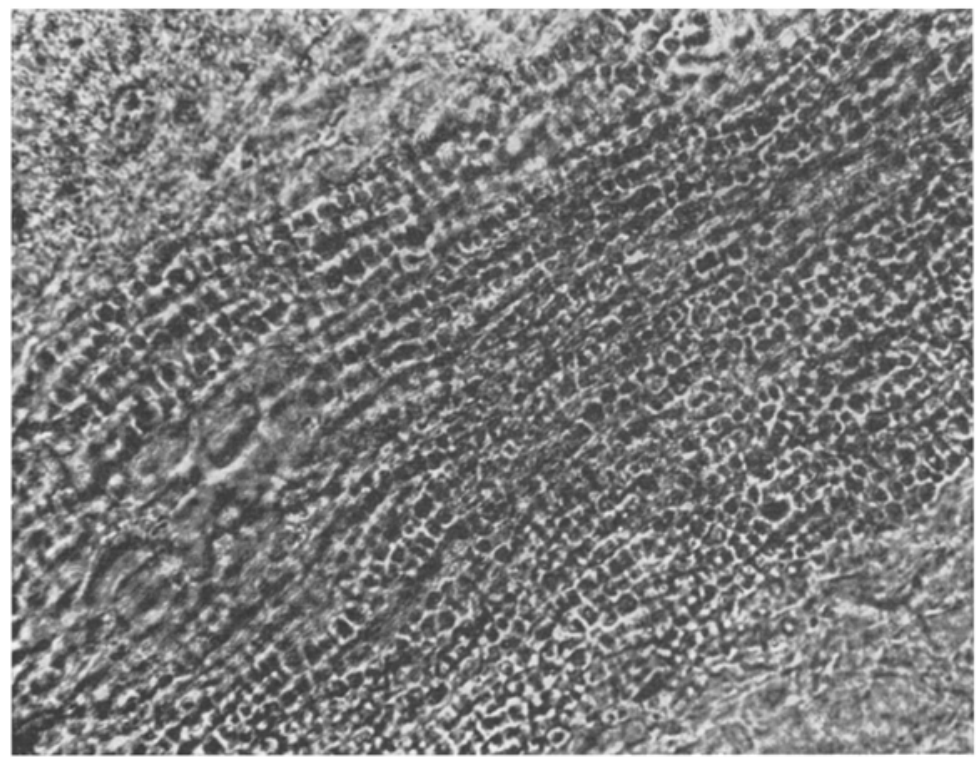

Fig. 3. KOH mount of hair from W.G. $(\times 269)$. Large endothrix spores in rows lying along the long axis of the hair. 


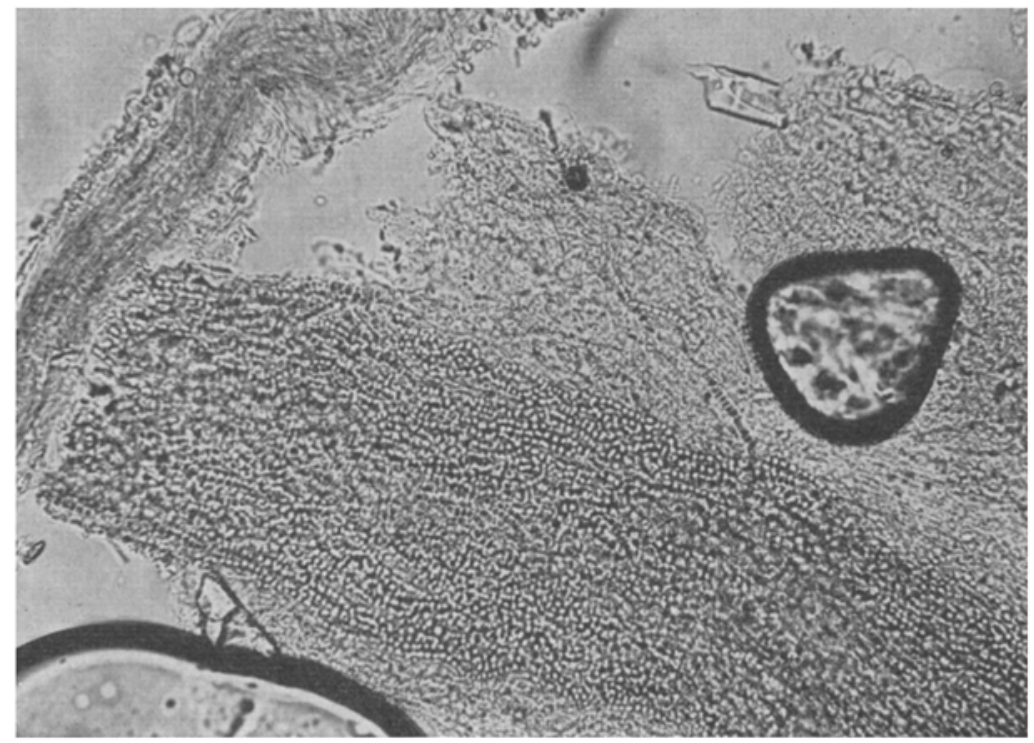

Fig. 4. KOH mount of specimen from W.G. $(\times 113)$. Infected hairs are seen embedded in scale that also shows hyphae and arthrospores.

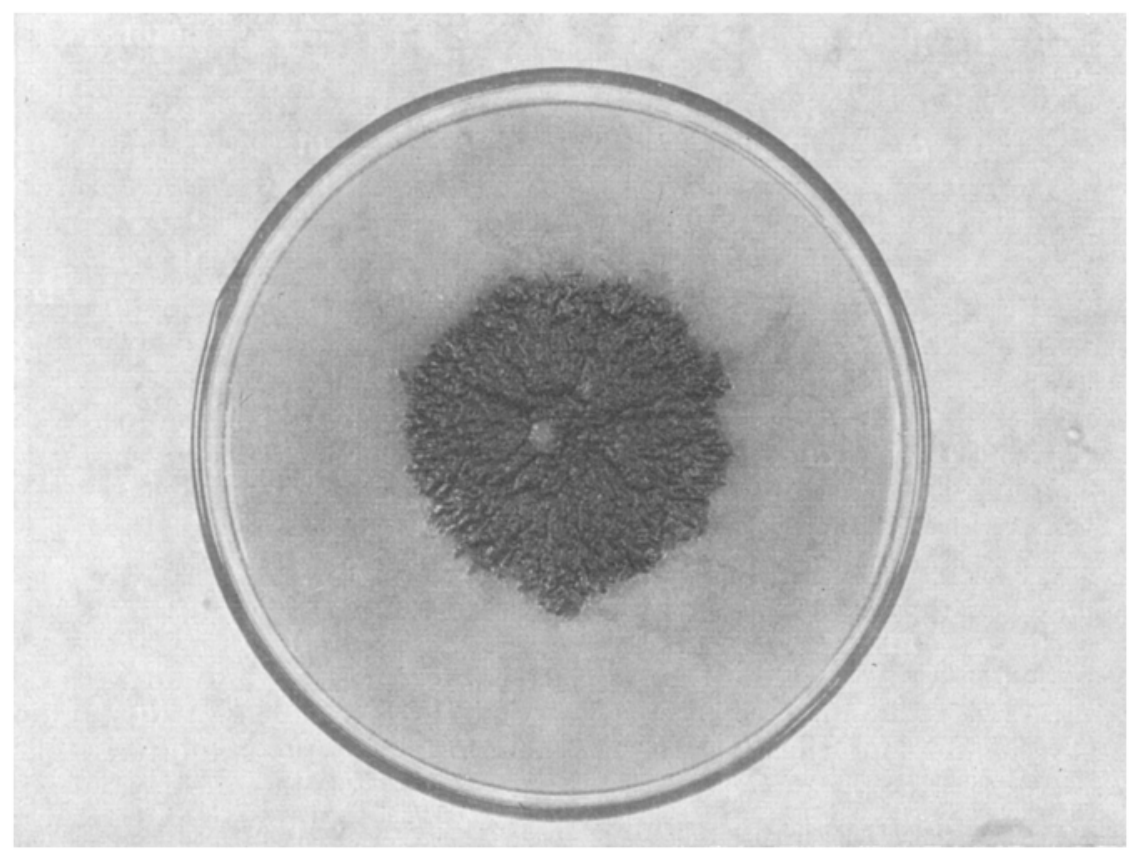

Fig. 5. Five weeks' growth on Sabourauds'dextrose agar of an isolate of Trichophyton violaceum from the reported outbreak. The colony is characteristically glabrous, cerebriform and deeply violaceou 
more frequently in association with scales that might also show invasion by hyphae and "strings" of arthrospores (Fig. 4). This is similar to the experiences of DONALD (55) and our own (56) in direct examinations of hairs with endothrix infection. In $\mathrm{KOH}$ mounts, the search for fungal elements in these cases is best conducted among the scales with embedded hairs.

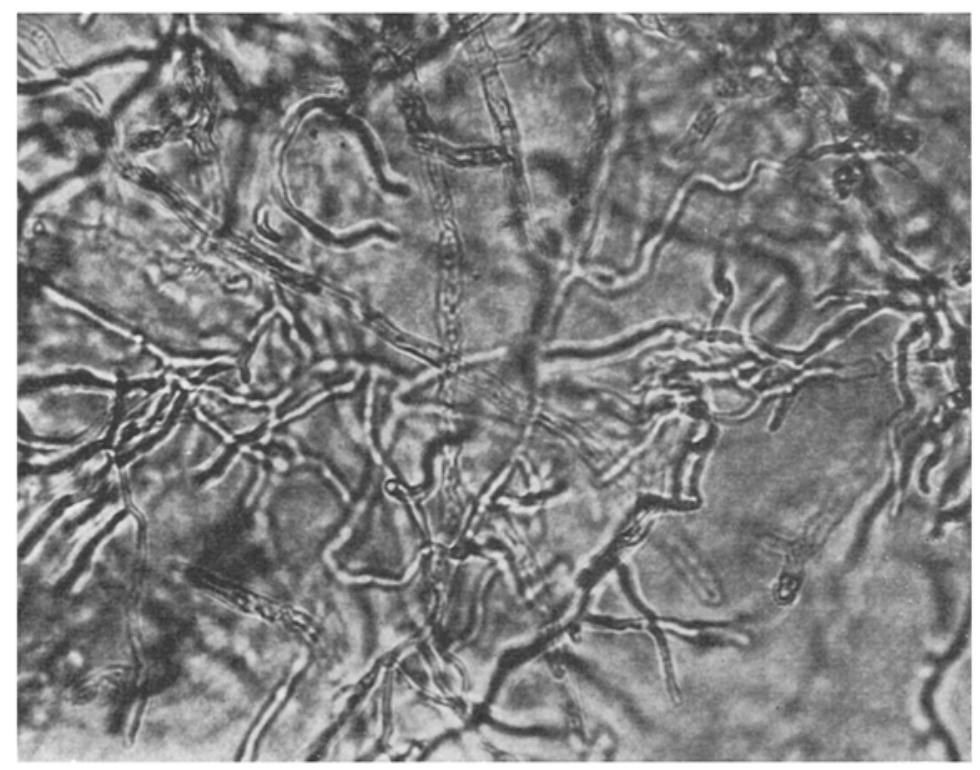

Fig. 6. Culture mount from a colony of Trichophyton violaceum $(\times 269)$. Barren hyphae are seen.

The strains grew slowly on Sabouraud's dextrose agar, attaining initially visible growth in six days and of $3-4 \mathrm{~cm}$ diameters, in five weeks. The characteristic violet purple pigmentation usually appeared in two weeks. Fully developed colonies (Fig. 5) were glabrous, raised, cerebriform, and deeply violaceous. Culture mounts from these colonies showed essentially barren hyphae (Fig. 6) except for a few chlamydospores.

\section{Treatment with Griseofulvin}

The five infected children were treated with griseofulvin (Fulvicin). The regimen consisted of daily oral doses of $0.25 \mathrm{~g}$ griseofulvin twice a day for the first week, then raised to and maintained at $0.25 \mathrm{~g}$ four times a day. This daily dose of $1 \mathrm{~g}$ of the antibiotic was given regardless of the age and weight of the child. No local medication was applied. The hair of the boys was clipped off at the third week of therapy. 
Slight initial clinical improvement with diminished scaling was observed at the end of three weeks' treatment, at which time the mycological examinations became negative except for one child (B.C). From then on to the nineteenth week after the start of therapy, repeated attempts to isolate the organism from all the children failed. The administration of griseofulvin was stopped after eight weeks with a total dose of $52.5 \mathrm{~g}$. Four weeks after the cessation of medication the children were clinically clear, with regrowth of hair. The boys, however, still showed minimal dry scaling which was controlled with simple shampooing. No untoward signs or symptoms indicative of intolerance to the drug were observed.

On one occasion, the $\mathrm{KOH}$ examination showed the sharp demarcation line between the proximal uninfected and the distal infected portions of hairs as observed in tinea capitis due to Microsporon audouinii after a few weeks' treatment with griseofulvin (57). A specimen of B.G. taken on the third week of therapy revealed hairs with this delimitation separating the healthy uninvolved proximal segment from the distal portion containing spores and short thick hyphae.

\section{Discussion}

There were two main factors leading to the discovery of this family outbreak of Trichophyton violaceum infection that, otherwise, would have remained a potential source of infection in the school, in the neighborhood, and among other contacts of these infected children. First was the alertness of the school nurse in recognizing the unimpressive clinical changes and referring the children for further studies. Second was the routine use of mycological procedures in suspected cases of tinea capitis. This awareness of the possible presence of mycotic scalp infection and the application of mycological examinations cannot be over-emphasized, particularly in the light of the reported spread and increase of endothrix infections $(56,58)$ which do not provide the distinct diagnostic advantage of fluorescence under Wood's light.

A noteworthy feature of this outbreak was the absence or inconspicuousness of the classical clinical hallmarks, the "black dots" and broken hairs. Only one child (L.M.G.) showed suspicious "black dots" and a mild inflammatory reaction. The two clinical changes found in all the children were dry scaling and partial alopecia. Thus, the failure to demonstrate the "black dots" and broken hairs does not necessarily rule out endothrix infection with Trichophyton violaceum. The case described by GREENHOUSE (39) did not show any "black dots" and only one of the 44 children involved in the epidemic reported by Rosenthal, Fisher \& Furnari (50) presented this morphological feature. PutKonen \& Blomouist (59) stated that "black dots" were a rare finding among their 24 patients in an epidemic in Helsinki. They gave the following clinical spectrum: 
$\begin{array}{lr}\text { "1. Scattered areas of alopecia } & 12 \\ \text { 2. Scaling patches without loss of hair } & 4 \\ \text { 3. Diffuse scaling } & 2 \\ \text { 4. Evidence of tinea after epilation } & \mathbf{1}, \\ \text { 5. No pathological findings } & \mathbf{5} \text { " }\end{array}$

DONALD (55), after admitting the extreme difficulty of clinically differentiating endothrix infection due to Trichophyton violaceum from that due to Trichophyton tonsurans in his series, described the following clinical pictures:

"1. Eight children showed rounded scaly areas with obvious partial alopecia.

2. Fifty-nine children and twelve adolescents showed small scaly plaques with scattered broken hairs.

3. Forty-five children, one adolescent and one adult showed patchy ill-defined plaques covered with adherent white scales. On casual inspection there was no obvious hair loss, but on close inspection occasional broken hairs could be found.

4. Eighteen children and two adults showed diffuse pityriasiform scaling without apparent hair loss. In these cases, broken and twisted hairs were present in the scale and could be demonstrated microscopically.

5. Six children and four adults showed scalps which were free from scale when examined, but on close inspection comedone-like black masses could be seen in some follicular orifices. Such distended follicles were usually raised above the scalp surface and simulated keratosis pilaris. All these patients were brunettes.

6. Ten children showed scattered follicular pustules and adherent crusts; in six, hair involvement was not detected clinically.

7. Two children showed multiple inflamed and edematous areas of kerion reaction."

In our larger series of cases with tinea capitis caused by Trichophyton tonsurans, we similarly had little success in demonstrating "black dots." The label of "black dot" ringworm, commonly attached to endothrix infections due to Trichophyton tonsurans and Trichophyton violaceum should not be misconstrued to denote the presence of "black dots" in every case and the necessity of demonstration for a clinical diagnosis. At best, their demonstration is a clue; cultural isolation of the causative fungus must be accomplished to warrant an absolute diagnosis.

The clinical picture presented by the cases in the present outbreak was easily that of seborrheic pityriasis capitis. The case described by Muskatblit (36) was diagnosed and treated previously as seborrheic dermatitis. Other authors emphasized the close similarity of the two conditions and DoNALD (55) regarded the scurfy head as most commonly suggestive of endothrix infection.

When these children first came to the Clinic, we were studying a group of children with tinea capitis caused by Trichophyton tonsurans. Because the clinical appearance simulated cases included in the group with trichophytosis caused by $T r$. tonsurans, we unhesitatingly included the children in the latter group. Only after the isolation of the causative organisms did we realize we were dealing with trichophytosis caused by $T r$. violaceum. The clinical changes caused by these two Trichophytons closely resemble each 
other and defy clinical differentiation. They usually are described together as endothrix or "black dot" ringworm.

Trichophyton violaceum is anthropophilic and the transmission of the disease is from human to human by either direct or indirect contact. A marked tendency of the infection to familial and institutional incidence because of closer personal contacts has been observed $(11,50,59,60)$. The survey of the two schools attended by the children presently studied was done in an attempt to uncover any possible outbreak in the school and trace the source of infection of the family. Except for the single isolation of Trichophyton violaceum and Trichophyton tonsurans from one girl, the significance of which remains a matter of conjecture, no evidence of infection with Trichophyton violaceum was found in the schools. This negative survey and the denial of the mother that any neighborhood playmates of the children had similar scalp conditions did not afford any clue to the origin of the outbreak. The organism is neither indigenous nor endemic in Michigan and inasmuch as the appearance of the organism was frequently associated with population movements, it may be surmised that the original source of the present outbreak came from outside Michigan. The introduction of trichophytosis caused by $T r$. tonsurans into Michigan has been attributed to migrant workers from Mexico and southwestern United States (61); and, according to LEwIS et al (62), most of the cases due to Trichophyton violaceum in the United States were found among immigrants and their siblings.

As with trichophytosis caused by $T r$. tonsurans, infection caused by Trichophyton violaceum is characterized by a torpid and chronic course. There is spontaneous involution at puberty, but not as marked as in Microsporon audowinii infection, for there are a certain number of females who carry their infection to adulthood. Trichophytosis caused by $T r$. violacenm is rare in adult males. Before the advent of griseofulvin, the infection was notoriously resistant to treatment and required $x$-ray epilation for a cure $(10,55,59)$. Griseofulvin undoubtedly has become the present treatment of choice and remarkable results have been obtained with its therapeutic use $(55,63,64,65,66,76)$. ZipRkowskI et al (68) achieved notable success in mass treatment with griseofulvin of 441 cases of Trichophyton violaceum infection in an Arab village in Israel. With a single oral daily dose of $25-30 \mathrm{mg} / \mathrm{kg}$ body weight, the majority of the cases presented clinical improvement after three weeks' treatment and at the end of eight weeks, 99 percent of the patients were cured. After ten weeks' therapy, all the cases were clear of infection. No relapse was observed during the follow-up of the first 25 cases for 2-6 months after therapy.

In the present series, clinical improvement with griseofulvin therapy lagged behind the sterilization of the lesions as indicated by mycological examinations. The children continued to show scaling and partial alopecia for a few weeks after the initial conversion of 
the repeated mycological studies to negativity during therapy. In accordance with our experiences in the treatment of tinea capitis due to Microsporon audouinii with griseofulvin, clipping of the hair after 2-3 weeks of therapy and shampooing of the scalp were helpful in this group.

With the attainment of clinical and mycological cures in each individual case of this outbreak by the administration of griseofulvin, the constant threat posed by the family as a source of further spread of Trichophyton violaceum infection in the school and in the community was eliminated. This underscores the value of griseofulvin in controlling epidemics and erasing endemic areas of tinea capitis due to dermatophytes.

\section{SUMMARY}

An outbreak of tinea capitis caused by Trichophyton violaceum in five siblings of a family of eight in Michigan and its control with griseofulvin are described.

\section{References}

1. Pinetti, P.: Distribuzione e diffusione di Trichophyton violaceum (Bodin) nelle diverse parti del mondo. Rass. Med. Sarda $61: 293,1959$.

2. Ajezio, L.: Geographic distribution and prevalence of the dermatophytes. Ann. N.Y. Acad. Sci $89: 30,1960$.

3. D'ARCA, S.: Rassegna sulla epidemiologia delle tricofizie nei vari paesi del mondo. Nuovi Ann. D'Igiene e Microb. $8: 205,1957$.

4. DE Olfveira, H.: A endemia portuguesa de tinha. Suas caracteristicas etiologicas. Acta Dermosifil. $45: 479,1954$.

5. Miguens, M. P.: La micologia en España. Revisión de la bibliografía desde el año 1946 al 1956. Mycopathol. et Mycol. Appl. $9: 23,1958$.

6. Rangue, J. \& Temime, P.: État actuel des dermatomycoses dans la région marseillaise. Sém. Hop. Paris $33: 2290,1957$.

7. Pinetti, P.: Rivista critica della letteratura micologica media en Italia tra el 1946 ed il 1956. Mycopathol. et Mycol. Appl. 11 : $155,1959$.

8. Lovzidou, M.: Trichophytie der Kopfhaut und des Körpers (hundert Fälle). Zbl. Haut- und Geschlkr. 61:619, 1939.

9. Richter, R.\&ERBAKAN, N.: Der heutige Stand der medizinischen Mykologie in der Türkei. Mycopathol, et Mycol. Appl. $10: 41,1958$.

10. Dostrovsky, A., KallNeR, G., Raubitschek, F. \& SAgher, F.: Tinea capitis. An epidemiologic, therapeutic and laboratory investigation. J. Invest. Derm. $24: 195,1955$.

11. Mikhall, G.R.: Tinea capitis. A mycological study of three hundred and three cases. J. Egyptian med. Assn. 37 : 538, 1954.

12. CataneI, A.: Sur la flore parasitaire des trichophyties en Algérie, Bull. Soc. Path. Exot. 32 : 117, 1939.

13. Coutelen, F., Cochet, G., Biguet, J., Mullet, S., Doby-Dubots, M. \& DEBLock, S.: Contribution à la connaissance épidemiologique et mycologique des teignes infantiles de Tunisie. Ann. Parasit. hum. comp. $31: 449,1956$.

14. Levy-LebHar, G. \& Levy-Lebhar, J.P.: Les teignes du cuir chevelu au Maroc, Maroc Méd. $35: 3,1956$.

15. GrIN, E. I. \& OžEGOVIĆ, L.: Critical survey of mycological research and literature in Yougoslavia up to 1957. Mycopathol. et Mycol. Appl. 9 : 341, 1958.

16. Popoff, L. CHr.: Etude sur les trichophyties en Bulgarie (surtout les teignes tondantes) au point de vue clinique et parasitologique. Godishnik Med. Fac. Univ. Sofia $7: 1,1928$. 
17. Nicolad, S.: Etude sur la trichophytie de cuir chevelu en Roumanie (Trichophyton violaceum). Ann. Derm. et Syph. 10:609, 1909.

18. Miedzinski, F. \& Lipski, J.: The mycosis as a therapeutic problem. Survey of 348 cases. Brit. J. Derm. $68: 200,1956$.

19. Kasmin, P. N.: Review of works on medical mycology published in the U.S.S.R. between 1946-56. Mycopathol. et Mycol. Appl. 10:227, 1959.

20. Mu, J. W. \& Kurotchiкin, T. J.: Statistical and mycological studies of dermatomycoses in Peiping. Chin. med. J. $55: 201,1939$.

21. Gokhalay, B.B., Padhye, A. A. \& Thirumalacher, M. J.: Trichophytonviolaceum infection of the scalp in Poona (India). Mycopathol. et Mycol. Appl. $14: 57,1961$.

22. BEHL, P. N.\& Sharma, M. D.: Incidence of mycotic infections in Delhi. Indian J. Derm. $3: 5,1957$.

23. DONALD, G, F.: A warning on the frequency of endothrix tinea capitis among the aboriginal and part-aboriginal population of South Australia. Med. J. Austr. $2: 435,1959$.

24. Donald, G. F., Sheppard, R.A.W. \& Brown, G. W.: A survey of 581 derma. tophytes identified in South Australia during the years 1954 to 1959. Austr. J. Derm. $5: 81,1959$.

25. DE OLIVEIRA, H.: Contribução para o estudo dos dermatófitos portugueses. VI. Etiologia da tinea capitis no centro de Portugal. Coimbra Med. 5 : 541, 1958.

26. DE Almeida, F., Da Silva Lacaz, C., \& Costa, O.: Dados estatísticos sobre principais micoses humanas observadas em nosso meio. An. Fac. Med. Univ. São Paulo $24: 39,1948-1949$.

27. Rossetri, N.: Um novo problema, sanitario em São Paulo. Primeiros resultados de um inquerito sobre as tinha. Rev. Inst. A. Lutz $1: 257,1941$.

28. BLANx, F.: Endothrix ringworm endemic in rural eastern Quebec Canad. J. Publ. Hith. $49: 157,1958$.

29. Crayg, G.E., Blank, F., \& Danby, C.W.E.: Tinea capitis due to species of the genus Trichophyton. Canad. Med. Assn. J. 65 : 480, 1951.

30. Negroni, P.: Desarollo de los estudios micológicos en la Argentina en el ultimo decenio. Mycopathol. et Mycol. Appl. 8 : 216, 1957.

31. Mackinnon, J. E.: Estadisticas sobre 1000 casos de micosis cutaneas en el Uruguay y determinacion de los especies de causantes. Ann. Inst. Hig. Montevideo $3: 83,1950$.

32. Mtranda, H. \& Troncoso, M.: Revisión de los casos de micosis estudiados en el Peru en el decenio 1946-1956. Mycopathol. et Mycol. Appl. 9 : 56, 1958.

33. VIDAx, R. V. Diagnóstico micológico de las tiñas del cuero cabelludo; datos históricos. Rev. Cubana Lab. Clin. $6: 416,1952$.

34. Gonzalez OchoA, A.\& Romo Vazouez, B.: Dermatofitos causantes de tiña de la piel cabelludo en la ciudad de México. Rev. Inst. Salub. Enferm. Trop. $6: 145,1945$.

35. LEwIs, G. M.: Ringworm of the scalp: curability, without depilating measures of infections caused by "animal" Microsporons. Amer. J. med. Sci. 189:364, 1935 .

36. MUskatblit, E.: Combined fungous infections. Report of six cases with a review of thirty-six cases from the literature. Arch. Derm. Syph. $44: 631,1941$.

37. Muskatblit, E.: Tinea capitis due to Trichophyton violaceum. Arch. Derm. Syph. $63: 391,1951$.

38. Werdman, F. D.: Ringworm of the scalp occurring in an adult. Arch. Derm. Syph. $13: 447,1926$.

39. GREenhouss, J. M.: Trichophyton violaceum infection of scalp and glabrous skin of an adult. Arch. Derm. Syph. 63:503, 1951.

40. REISs, F.: Trichophyton tonsurans ringworm: a contribution to the epidemiology and rare clinical manifestations. Brit. J. Derm. 66 : 239, 1954.

41. Franks, A. G. \& TASchojIAN, C. L.: Incidence and etiology of tinea capitis. Special reference to Trichophyton tonsurans. Arch. Derm. 74:349, 1956.

42. Greenwood, A. M.: Report on cultures of parasitic fungi. Arch. Derm. Syph. $8: 81,1923$. 
43. Downing, J. G., BaIrd, J. W. \& Pacr, D.: Fungous diseases in the Boston area. New England J. Med. 243:564, 1950.

44. Tobias, N.: Ringworm of the scalp. A clinical survey. Missouri Med. $53: 21$, 1956 .

45. Lemmann, C. F, Pipkin, J. L. \& Ressmann, A, C.: Cultural survey of tinea capitis in San Antonio, Texas. Arch. Derm. Syph. $61: 488,1950$.

46. PipkIN, J. L.: Tinea capitis in the adult and adolescent. Arch. Derm. Syph. $66: 9,1952$.

47. Polsky, M.: Office mycology. Report on 1000 cultures taken in a general dermatologic practice. Texas St. J. Med. 49:696, 1953.

48. Pinkerton, M. W., Mullins, J. F. \& Shapiro, E.M.: The ecology of superficial fungus infections in Galveston, Texas; a five year survey. Texas Rep. Biol. Med. 15: 26,1957 .

49. Hazen, E. L., Little, G. N. \& Mordaunt, V.: Annual Report, Division of Laboratories and Research, New York State Department of Health, Albany, New York, 1956, pp. 95-97.

50. Rosenthal, S. A., Fisher, D. \& Furnari, D.: A localized outbreak in New York of tinea capitis due to Trichophyton violacenm. Arch. Derm. 78:689, 1958.

51. CAwLEx, E. P.\&HORNE, S. F.: Concurrent fungous infection of the skin. Arch. Derm. Syph. $59: 667,1949$.

52. GEORG, L. K., HAND, E. A. \& MENGES, R. A.: Observations on rural and urban ringworm. I. Invest. Derm. 27:335, 1956.

53. Bосово, F. C. \& CurTrs, A. C.: Accidental isolation of Trichophyton mentagrophytes from the floor of a schoolhouse. Mycologia 50:164, 1958.

54. Mackenzie, D. W. R.: The extra-human occurrence of Trichophyton tonsurans var. sulfuretm in a residential school. Sabouraudia $1: 58,1961$.

55. Donald, G. F.: The history, clinical features and treatment of tinea capitis due to Trichophyton tonsurans and Trichophyton violaceum. A.ustr. J. Derm. $5: 90,1959$.

56. Mredter, L. J., BocoBo, F. C. \& EAdie, G. A.: Trichophyton tonsurans infection of scalp. J. Mich. St. Med. Soc. 59 : 1851, 1960.

57. Harreld, E. R. Bocobo, F. C., Kingery, F. \& Mredler, L. J : Effect of griseofulvin on tinea capitis caused by Microsporm audowini. Arch. Derm. 81 : 797, 1960.

58. GEorG, L. K.: Trichophyton tonsurans ringworm - a new public health problem. Pub. Hith. Rep. 67:53, 1952.

59. PutKonen, T. \& Blomgurst, K.: Trichophyton violacetm infection in a home for mental defectives in Helsinki. Arch. Derm. Venereol. 39 : 310, 1959.

60. RaUBITSCHEK, F.: Infectivity and family incidence of black-dot tinea capitis. Arch. Derm. $79: 477,1959$.

61. HAND, E. A. \& GEORG, L. K.: Trichophyton tonsurans ringworm. J. Mich. St. Med. Soc. $54: 687,1955$.

62. Lewis, G. M., Hopper, M. E., Wrlson, J. W. \& Plunkett, O. A.; An Introduction to Medical Mycology, 4th Edition, The Year Book Publishers, Inc., Chicago, Illinois, 1958, p. 62 .

63. Sagher, F., Raubitschek, F. \& Axelrad, B.: Griseofulvin treatment of tinea capitis due to $T$. violaceum. J. Trvest. Derm. $33: 85,1959$.

64. LevY-LebHaR, G., Levy-LEBHAR, J. P. \& HERMAN, M.: Le traitement des teignes au Maroc par la griseofulvine. Maroc Méd. 38 : 1603, 1959.

65. PIPKIN, J. L.: The treatment of endothrix Trichophyton infections with griseofulvin. Arch. Derm. $81: 813,1960$.

66. DesaI, S. C.: Effect of griseofulvin on Trichophyton rabrum and Tyichophyton violaceum infections. Arch. Derm. $81: 849,1960$.

67. Shternlukht, L. A., Sayelleva, T. L., Frolova, M. A. \& Zetmanov, R. B. Griseophalvin therapy of patients with dermatomycosis. Vestnik Derm. Venereol. $35: 39,1961$.

68. Zrprkowski, L., Krakowski, A., Schewach-Mrtlet, M. \& BTEsh, S.: Griseofulvin in the mass treatment of tinea capitis. Bull. World IIlth. Org. $23: 803$, 1960 . 